the vinyl support. I remember Prof. Kalman testing different Shure phono cartridges and showing me their subtle audio differences.

The years spent at CMST with Prof. Kalman have had a lifelong influence in my career. Even though I eventually moved from pure mathematics to business applications, I have always remembered and tried to be true to the rigor of his research. I was also influenced by his lifestyle of dual appointment in two continents when I decided to accept my two current academic appointments in Barcelona's IESE and Shanghai's CEIBS.

\section{AUTHOR INFORMATION}

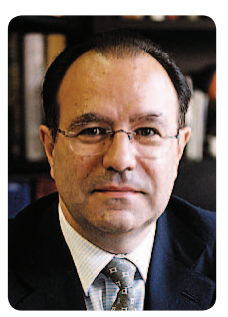

Jaime Ribera is a professor in the Operations Management Department at IESE Business School, University of Navarra, Spain, and a professor and the Port of Barcelona Chair of Logistics at CEIBS in Shanghai, China. He was awarded a Fulbright fellowship to pursue doctoral studies in the United States. He holds an
M.Sc. in operations research and a Ph.D. in ISE (mathematical systems theory) from the University of Florida and a Dr.Eng. in industrial engineering from the Polytechnic University of Catalonia, where he is an associate professor. He was the deputy dean for faculty at the IESE Business School from 1993 to 2001, president of the European Operations Management Association (2003-2006), and secretary of the U.S. Operations Management Association (1992-1997). He served on the editorial boards of the International Journal of Operations and Production Management and is currently editor of the Harvard Business Review China and the International Commerce Review. His research interests lie in the areas of operations management improvement, health systems management, and project management. He has published teaching materials, academic research, casebooks, and textbooks. He has been active in consultancy in process improvement, supply chain management, and project management and has extensive experience working with private and public companies. He is the president of the Board of Caixa Terrassa, a savings bank in Spain.

\title{
R.E. Kalman: A Great Human Being
}

\section{A. BÜLENT ÖZGÜLER}

came to know about Prof. Kalman through a Turkish post-doc of his during my M.Sc. studies at Middle East Technical University. When I learned that I was accepted to carry on my doctoral studies under his supervision, I was excited, happy, and very scared.

I met him for the first time in March 1979 in his office and found out that he was no werewolf, just an ordinary middle-aged man and a nice person. The Turkish post-doc's stories of him seemed exaggerated! I remember he congratulated me for the fact that I had already published three articles from my M.Sc. thesis in the field of system theory, but that I should learn more mathematics at CMST (Prof. Kalman's research center at the University of Florida). At the first seminar I attended at CMST his advice sank in; I was totally intimidated by the level of mathematics and rushed to register for a course on abstract algebra.

Things that I gradually realized about Prof. Kalman were that all secretaries hate him, and many colleagues find him rude. What we see now in person is a tamed version. He is very energetic and puffs like a steam engine locomotive in the corridors. He is very proud of his personal library. He has done research on the mechanics of turntable needles.

Digital Object Identifier 10.1109/MCS.2010.935897
He eats a lot of yogurt. He is a sound-system freak. He loves to shock people by answering their letters in their native languages instead of English-I once wrote a Turkish letter for him.

I had few personal interactions with him concerning my thesis study at the University of Florida. He focused on econometrics at the time, and I learned most of the technicalities concerning my thesis topic from Pramod Khargonekar rather than from him. But he did determine my thesis topic. I went into his office and told him I could write my dissertation on one of two topics, either on a fractional approach to optimal control or on algebraic regulator theory. He listened to my summary of the results that could be included in my thesis on optimal control and said “Oh, oh! But you are neither avoiding spectral factorization nor the Riccati equation. Real progress on optimal control would come if one can avoid them altogether!" That decided it.

Years later after my return to Turkey, I had a phone call from him. He was invited for a visit to Ankara, and he wanted to get together on his arrival. At the dinner given for his honor, there was some discussion on whether the following day he should visit a museum or visit me at Bilkent University and see the campus of the first private university in 
Turkey. He concluded the discussion after a while "No, no, no! I would like to go to Bülent University."

\section{AUTHOR INFORMATION}

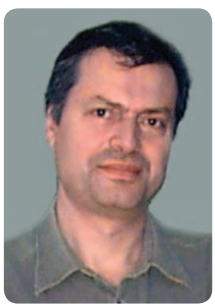

A. Bülent Özgüler is with the Electrical and Electronics Engineering Department at Bilkent University. He received the Ph.D. from the University of Florida, Gainesville, in 1982. He was a researcher at the Marmara Research Institute of TÜBITAK from 1983 to 1986. He spent one year at the Institut für Dynamische Sys- teme, Bremen Universitt, Germany, on an Alexander von Humboldt scholarship during 1994-1995. He has been with the Electrical and Electronics Engineering Department of Bilkent University, Ankara, since 1986. He was chair of the department from 1997 to 2006. He joined Bahçeşehir University in 2008, on leave from Bilkent University. His research interests are in the areas of decentralized control, stability robustness, realization theory, linear matrix equations, and application of system theory to social sciences. He has written over 60 research papers and is the author of Linear Multichannel Control: A System Matrix Approach (Prentice Hall, 1994).

\section{Memories from My Gainesville Days as a Student of R.E. Kalman}

\section{TRYPHON T. GEORGIOU}

graduated from the National Technical University of Athens in June of 1979. In the spring of 1979, shortly after I

had expressed interest in joining Prof. Kalman's group at Gainesville, I met and was vetted by his former student Thanos Antoulas during one of Thanos' visits to Athens. I still have notes from that meeting, where I came to realize the beauty and breadth of the research program that I was soon going to be part of. I went to Gainesville in the fall of 1979 and was welcomed by fellow students Pramod Khargonekar, Bülent Özgüler, Jaime Ribera, and Erol Emre, who was R.E. Kalman's postdoc at the time. I met Prof. Kalman a month later when he returned to Gainesville from a trip. I distinctly recall that first meeting. After inquiring briefly about my own (limited at the time) research experience, he went on to discuss the importance of mathematics in engineering and science. He touched on modeling and how to discover structure from data as well as the fundamental role of minimality, both in the complexity of models as well as in our assumptions in developing them. Yet, with that in the background, he suggested that I take advanced algebra courses first, the importance of which became clear to me much later. From that point on, and for about a year, my interaction with Prof. Kalman was minimal. Apparently, he allowed time for osmosis to take place.

The Center was a remarkable place. Frequent visitors, seminars, together with an absolutely invaluable resource, Prof. Kalman's personal library and collection of preprints/ reprints, provided a unique environment for learning. One cannot overemphasize the tremendous benefit that we drew simply from being in charge of this collection of papers, with books organized according to LC classification and papers following his own system. The breadth of ideas and topics that I was exposed to provided the basis for much of my subsequent development. I recall that among his

Digital Object Identifier 10.1109/MCS.2010.935898

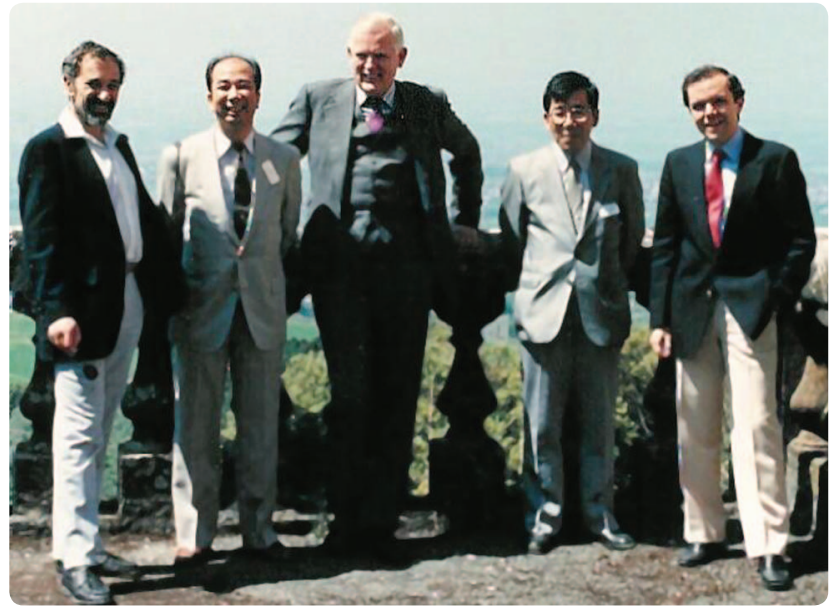

A student reunion. (From left) Eduardo Sontag, Yutaka Yamamoto, Rudolf Kalman, Tsuyoshi Matsuo, and Thanos Antoulas attending the conference held in honor of Rudolf Kalman in Frascati, Italy, in May 1990.

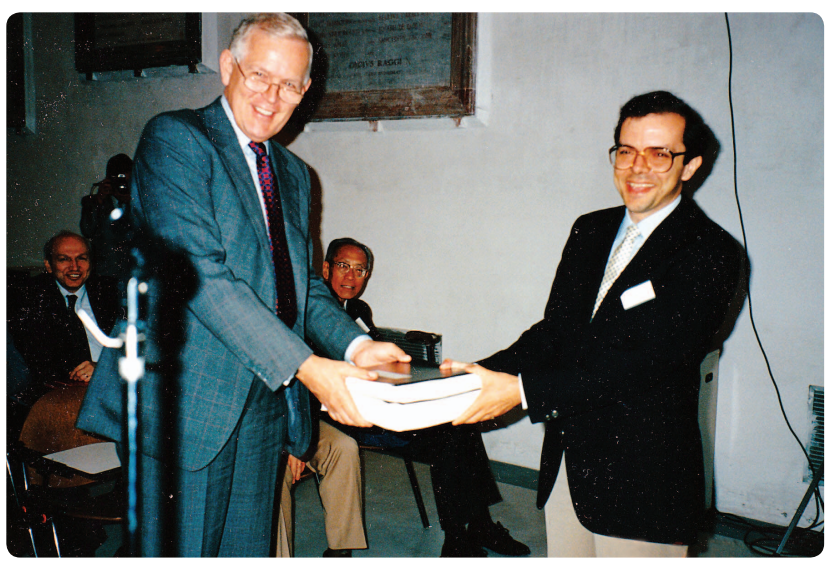

Rudy Kalman receiving from Thanos Antoulas a draft of the book Mathematical System Theory: The Influence of R.E. Kalman, published by Springer, during the conference held in his honor in Frascati, Italy, in May 1990. 